\title{
Family planning provision in the Trent health region: Is it accessible to school aged teenagers?
}

\author{
Jane Allen, BSc, PGCssrm, Research Officer; Sue Bradley, MSc, BSc, RGN, RSCN, RHV. Lecturer \\ School of Community Health Sciences, The Medical School, The University of Nottingham, Nottingham, UK.
}

Correspondence: Jane Allen, Research Officer, Rise Park Surgery, Rise Park, Nottingham, NG5 5EB, UK. Tel: 0115

9550112, Fax: 0115 9797056, Email: risepark@doctors.org.uk

(Accepted April $7^{\text {th }}, 2000$ )

\begin{abstract}
Summary
Strategies to combat existing high teenage pregnancy rates in the UK need to include contraceptive services that can be easily accessed by young people, including those who are still at school. This study concerns the availability of family planning services to young people who are still at school. One hundred and eight family planning clinics in the Trent region were surveyed to determine their clinic opening hours. Hours accessible to school aged young people were identified as being services provided during school lunch breaks, after school and at weekends. A total of 498 weekly hours of provision were identified, and 260.5 of these were accessible to school aged young people. There was a lot of variation between health authority areas both in terms of the number of hours accessible to this age group and also in terms of the percentage of clinics not offering any service accessible to school aged people.

The recent report from the Social Exclusion Unit identified accessible contraceptive services as part of its strategy to reduce teenage pregnancy rates in the UK. Although these results are descriptive and do not intend to show any causal relationship, they do show that in all health authority areas there are clinics that are not providing any service that is accessible to school aged young people.
\end{abstract}

\section{Key words}

accessibility of services, contraception, teenage pregnancy, young teenagers

\section{Key message points}

- At the point of data collection, there were family planning clinics in all of the health authorities studied that did not offer any hours of service that were accessible to school aged teenagers.

- In some areas large centrally based clinics provided a substantial amount of the provision, but this may be inaccessible to school aged teenagers from outlying areas.

\section{Introduction}

Despite growing efforts within political and health arenas, conceptions in the under 16 age group have increased from 8.3:1000 in 1994 to $9.4: 1000$ in $1996 .^{1,2}$ In 1997 almost 7700 conceptions were to the under 16 s, resulting in 3700 births. ${ }^{3}$ The recent major report published by the Social Exclusion Unit (SEU) ${ }^{3}$ describes England as having 'the worst record on teenage pregnancies in Europe', and highlights again the short- and long-term burden of teenage motherhood, both for young women and for society.

It is clear that many issues influence conception rates in this age group, related to both the individual teenager, and the context within which she lives. ${ }^{1,3,4}$ For some young women pregnancy is not necessarily regarded as unwanted. ${ }^{4,5}$ However, the high rate of therapeutic abortion in this age group suggests that many conceptions are unplanned and could have been prevented. ${ }^{6}$ There are significant links between deprivation and teenage pregnancy. However, the SEU also identifies issues such as low expectations, ignorance (both about sexual relationships and about services) and the 'mixed messages' of society and the media, as contributing to adolescent conception rates. ${ }^{3}$

Two further factors influencing conception rates are suggested to be the level of education received by young people, and the availability of appropriate contraceptive services. ${ }^{1,3,7,8}$ For the under $16 \mathrm{~s}$ in full time education there are obvious constraints upon their ability to access services. The SEU describes location and opening hours as 'critical for teenagers who may be tied to a school timetable and rely upon public transport'. ${ }^{3}$ Use of services may also be limited by embarrassment coupled with fears of exposure, judgmental attitudes and lack of confidentiality. ${ }^{3,6-8}$ In rural areas use of GP services may be further restricted by the knowledge that the teenager may possibly be seen by a neighbour or relative. ${ }^{8,9}$

Studies have suggested an inverse link between conception rates in teenagers and the provision of contraceptive services. ${ }^{7,10,11 .}$ The Effective Health Care Review of $1997^{1}$ places great emphasis on the need for contraceptive services to be tailored to local need, and to take into account the particular needs of adolescents. The SEU states that the first step is 'clearly to provide better access to contraception generally, ${ }^{3}$ and so key factors in the success of contraceptive services are: availability, accessibility, confidentiality and good publicity. ${ }^{1,9}$

This paper presents results describing the availability of family planning clinics to young people aged less than 16 years living in the Trent region of the UK. As such, it is not seeking to demonstrate cause and effect, but to critique service provision through an analysis of clinic opening hours.

\section{Method}

To examine the accessibility of family planning clinics to school aged young people (those aged 12-16 years) in the Trent health region, it was necessary to collect data on all family planning clinics in existence. Data collection took place in the autumn of 1997 and so all information given relates to services offered at that time.

Information was collected for all health authority areas in Trent excluding South Humber, and the researcher obtained the information through either the Community Health Trust or large centrally based family planning clinics. If detailed information on opening times was not made available at this point, then the researcher contacted each clinic by telephone.

The accessibility of a clinic was determined by its hours of service provision. To be accessible to school aged young people (defined as young people aged 12-16 years) a clinic needed to provide service in the periods $12.30 \mathrm{pm}$ to 1.30 
pm to cover school lunch times, and $4 \mathrm{pm}$ to $9 \mathrm{pm}$ for after school hours provision. Total hours provision and hours of provision accessible to young school aged teenagers per week were calculated. Where clinics did not run weekly sessions, equivalent weekly hours were calculated. Weekend clinics were also identified as being accessible to this age group, but these were relatively rare and a total of five Saturday clinics were recorded. Other services providing contraception were not included.

Data on rankings for conceptions to young women in each health authority area were also obtained for descriptive and contextual purposes. This information was supplied by NHS Trent and is derived from Office of National Statistics data.

\section{Results}

Data for the year 1994, derived from the Office of National Statistics, were used to obtain a national ranking for each health authority area (Table 1). These data show that on a national scale, Trent has four areas within its boundaries that are within the top 20 for conceptions to women under 16 years of age. There is a large amount of variation $\left(6^{\text {th }}\right.$ out of 100 to $62^{\text {nd }}$ out of 100), with Barnsley and Doncaster lying within the top 10, compared to Lincoln and Leicester which rank $56^{\text {th }}$ and $62^{\text {nd }}$, respectively. Trent is a diverse region as it embraces areas that can be described as urban, mixed, rural, mining and industrial. Table 1 gives the Townsend score for deprivation associated with each of the 10 areas, and again there is a large variation (-4.54 for Lincolnshire to +4.81 for Sheffield).

As these areas are so variable in terms of their under 16 conception rates, further descriptive analysis of family planning provision was undertaken to examine variation in hours of provision for this age group. Data were available for 108 family planning clinics, and these clinics provided a total of 498 hours of service. Table 1 gives the number of clinics in each health authority area, the total weekly provision and hours accessible to school aged teenagers, and the percentage of clinics that do not provide any family planning services that are accessible to this age group. Again there is a large difference between areas, and this is shown graphically in Figure 1.

In all 10 areas there were family planning clinics which were not accessible to school aged teenagers. This ranges from $7 \%$ to $62.5 \%$. The number of hours offered at each clinic also varied widely. In most areas there were large, often centrally based clinics offering substantially more teen hours. For example, in Sheffield, one clinic provided a total of 19 teen hours per week and the centrally based clinic in Nottingham also offered substantially more teen hours than other clinics in the area.

\section{Discussion}

The purpose of this analysis was to describe the accessibility of family planning services to young school aged teenagers through the clinic opening times. The government has highlighted teenage pregnancy as a problem and has produced strategies to combat existing high rates. ${ }^{3}$ One such target is to improve the accessibility of contraceptive services to teenagers. This descriptive analysis suggests that there are a number of family planning clinics within each health authority area in Trent that do not provide any accessible service to young people who are still at school. There are, however, other accessible services such as general practice and other specific local initiatives, which have not been considered in this paper. A true picture of the accessibility of school age contraceptive services in Trent would need a substantial audit of these services as well as those offered by family planning clinics. However, as previous research suggests that family planning clinics are a popular choice for young people aged less than 16 years, ${ }^{12}$ then their accessibility to this age group is an important issue.

It is important that sweeping judgements are not made on the basis of these data, as it cannot imply a causal relationships between provision of accessible hours to young teenagers by family planning clinics and high and low pregnancy rates. Other factors that are closely linked, such as deprivation, must always be taken into account when considering teenage pregnancy rates.

It is interesting that in all of the areas there are large, often centrally based clinics providing much of the service that is accessible to young teenagers. These centrally based clinics are likely to be served by public transport and reach a larger urban population. However, one study found that the distance needed to travel to a service is an important issue for this age group, ${ }^{13}$ and so this may isolate a large number of teenagers who do not live near to city centres. It is also interesting to note that there were very few weekend clinics running at the point of data collection and that some sessions were not run on a regular weekly basis. This has implications for the provision of emergency contraception, which requires the fairly rapid intervention of a health professional. $^{14}$

It is well known that many young teenagers are putting themselves at risk of pregnancy and STIs. The data given in

Table 1 Demographic information and hours of provision for each Health Authority area.

\begin{tabular}{|c|c|c|c|c|c|c|c|}
\hline $\begin{array}{l}\text { Health } \\
\text { authority area }\end{array}$ & $\begin{array}{l}\text { Ranking for } \\
\text { conceptions in } \\
\text { under } 16 \mathrm{~s} \text { in } \\
\text { England* }\end{array}$ & $\begin{array}{l}\text { Townsend } \\
\text { Score** }\end{array}$ & $\begin{array}{l}\text { Approximate } \\
\text { population of } \\
12-16 \text { year olds*** }\end{array}$ & $\begin{array}{l}\text { No. of } \\
\text { clinics }\end{array}$ & $\begin{array}{l}\text { No. }(\%) \text { of } \\
\text { clinics not } \\
\text { providing any } \\
\text { young teen } \\
\text { accessible service }\end{array}$ & $\begin{array}{l}\text { Total hours } \\
\text { of provision } \\
\text { (per week) }\end{array}$ & $\begin{array}{l}\text { Total hours } \\
\text { accessible to } \\
\text { young teenagers } \\
\text { (per week) }\end{array}$ \\
\hline Barnsley & 6 of 100 & 3.86 & 13,500 & 9 & $3(33 \%)$ & 45.5 & 22.5 \\
\hline Doncaster & 9 of 100 & 3.28 & 18,500 & 4 & $1(25 \%)$ & 18.25 & 10.5 \\
\hline Nottingham & 14 of 100 & 0.72 & 42,500 & 20 & $10(50 \%)$ & 66.5 & 31.5 \\
\hline Rotherham & 15 of 100 & 2.63 & 16,000 & 7 & $1(14 \%)$ & 43.75 & 17.25 \\
\hline Sheffield & 22 of 100 & 4.81 & 34,750 & 8 & $5(62.5 \%)$ & 76 & 26 \\
\hline South Derbyshire & 28 of 100 & -1.18 & 34,500 & 9 & $2(22 \%)$ & 38.75 & 21.75 \\
\hline North Nottingham & 28 of 100 & -1.92 & 23,500 & 14 & $2(14 \%)$ & 58.75 & 36 \\
\hline North Derbyshire & 34 of 100 & -3.03 & 21,000 & 13 & $2(15 \%)$ & 44 & 31 \\
\hline Lincolnshire & 56 of 100 & -4.54 & 35,750 & 15 & $1(7 \%)$ & 40.5 & 32.5 \\
\hline Leicestershire & 62 of 100 & -2.98 & 63,000 & 9 & $1(11 \%)$ & 66 & 31.5 \\
\hline Total & & & 302996 & 108 & 28 & 498 & 260.5 \\
\hline
\end{tabular}

* 1994 ONS data $* *$ Derived from 1991 census data *** Derived from ONS mid 1996 estimates 
Figure 1 Total hours of provision and total hours accessible to school aged teenagers

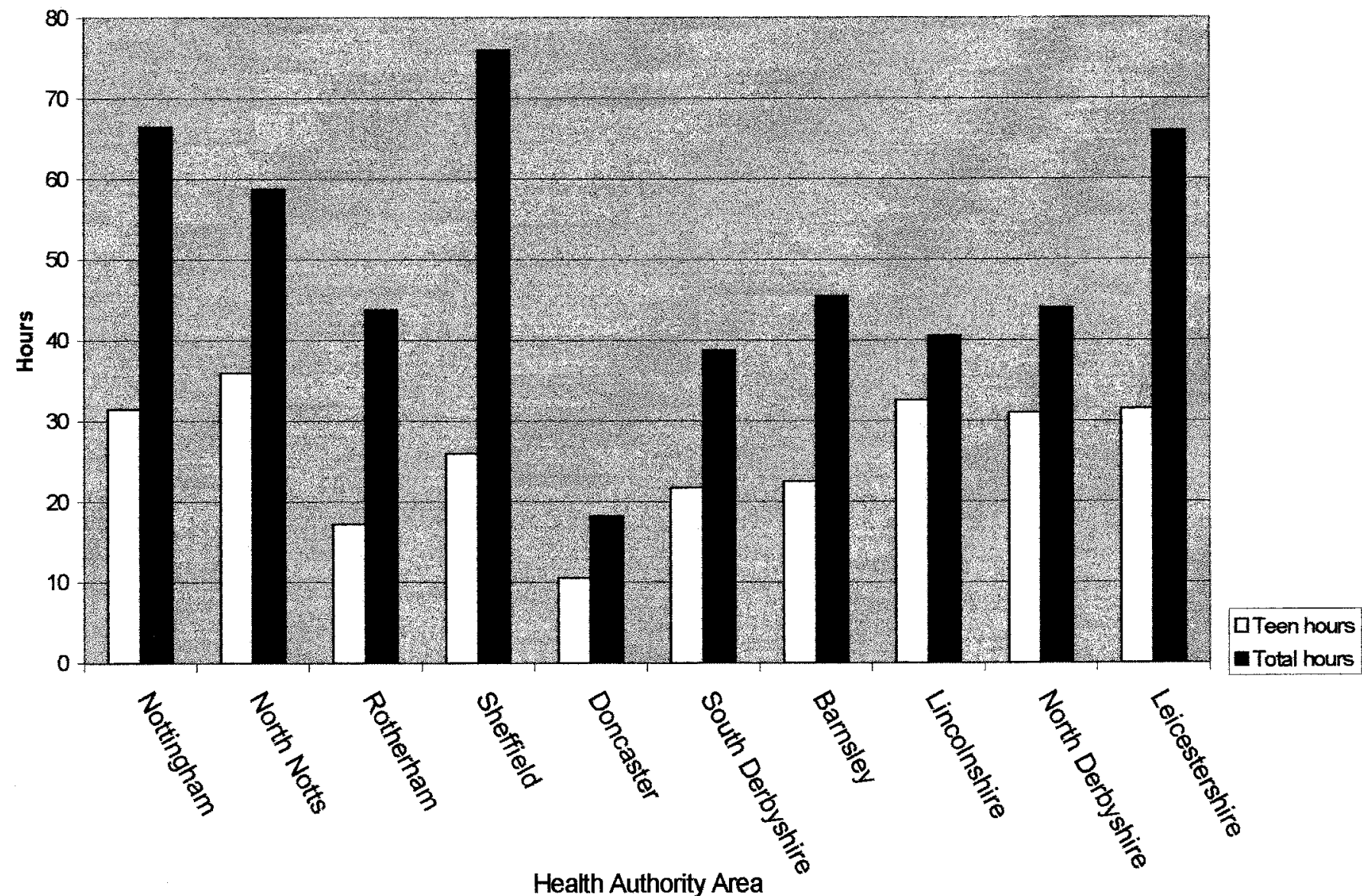

the SEU report suggests that only $50 \%$ of young people use contraception at first intercourse. ${ }^{3}$ If family planning clinics are seen by young teenagers as an acceptable venue for receiving contraception and contraceptive advice, ${ }^{12} 15$ then it is important that this service is made available to them. The SEU report has made accessible contraceptive services a priority and has identified opening hours as an important factor. It has also made moves towards targeting areas of high need, which is definitely relevant to Trent, which has large variations in conception rates, and also in levels of deprivation across the region. It is important, therefore, that providers are aware of the accessibility of services and it may be that as the government plans to identify high risk areas, then access issues such as opening times can be adapted to meet levels of need at a local and targeted level.

\section{Acknowledgements}

The authors would like to thank Dr Julia Hippisley-Cox and Professor Mike Pringle for their help and comments on the final manuscript, and Andy Nicholson from the Trent Regional Office for supplying the national data on conception rates.
Statements on funding and competing interests

Funding. This study was funded by NHS Trent Region R\&D as part of the Trent Teenage Pregnancy Study.

Competing interests. None

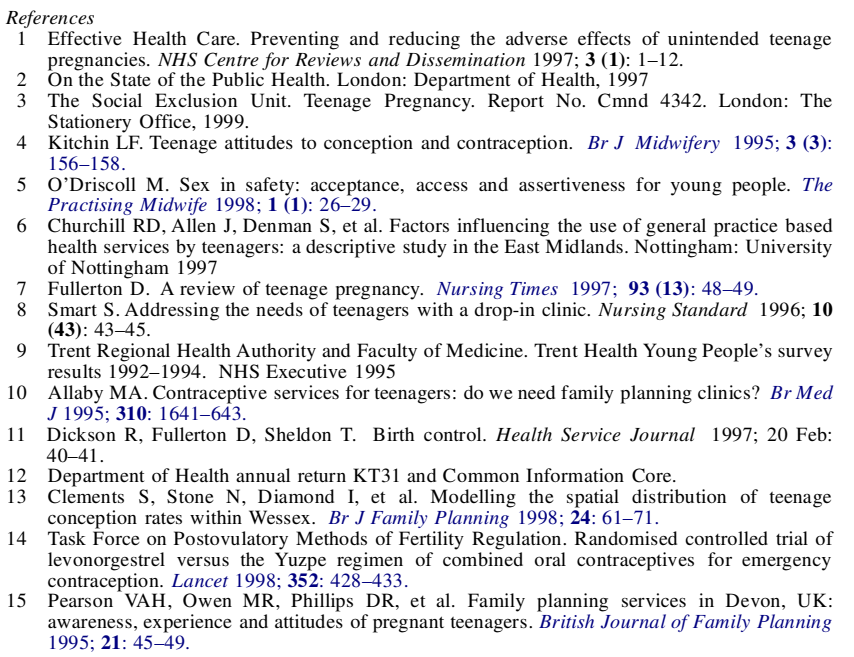
awareness, experience and attitudes of pregnant teenagers. British Journal of Family Planning 